\title{
Influence of Sea Ice Thickness on the Atmosphere in the Winter Arctic Region in an Atmospheric General Circulation Model
}

\author{
Yukimasa Adachi and Seiji Yukimoto \\ Meteorological Research Institute, Tsukuba, Japan
}

\begin{abstract}
The influence of sea ice thickness on the winter Arctic atmosphere has been investigated using an atmospheric general circulation model, focusing on heat fluxes at the sea ice surface. Due to heat conduction from the sea ice bottom, the sea ice surface temperature increases when the sea ice becomes thin. However, the heat balance among net longwave cooling, sensible and latent heat fluxes, and heat conduction changes with sea ice thickness. When the sea ice is thick, longwave cooling is balanced with the heating of heat conduction and downward sensible heat flux. When the sea ice is sufficiently thin, cooling by sensible and latent heat fluxes plays a large role in heat balance at the sea ice surface, canceling the increase of downward longwave heating associated with cloud change. It is suggested that thinner sea ice leads to warming of a large part of the troposphere in the Arctic region, causing a weakening of upper westerly wind in the sub-arctic region. The magnitude of such a wind response to possible sea ice thickness variability can be $10-20 \%$ of interannual variability.
\end{abstract}

\section{Introduction}

Projections using climate models (IPCC 2001) indicate that sea ice extent and thickness will likely decrease in the future due to global warming. Such a decrease is predicted to lead to a substantial warming in the polar region, possibly affecting extratropical atmospheric circulation.

The two aspects to consider regarding the effects of sea ice change on the atmosphere are sea ice area (concentration and extent) change and sea ice thickness change. Some early studies investigated the influence of sea ice concentration (Parkinson et al. 2001; Flato and Ramsden 1997) or extent (Magnusdottir et al. 2004; Alexander et al. 2004) on the atmosphere using an atmospheric general circulation model (AGCM). Parkinson et al. (2001) investigated the influence of the observation error of sea ice concentration, and found that sea ice concentration uncertainties of $\pm 7 \%$ could affect simulated regional temperatures by more than $6^{\circ} \mathrm{C}$. Flato and Ramsden (1997) investigated the differences in the treatment of the leads (the open water in the sea ice region), and discovered that surface air temperature increased by up to $5^{\circ} \mathrm{C}$ when the lead fraction was increased from $1 \%$ to near $5 \%$.

Observations of sea ice thickness are limited, although some observations have been conducted from submarines (e.g., Bourke and McLaren 1992; Rothrock et al. 1999; Winsor 2001). Rothrock et al. (1999) demonstrated that the mean ice draft (depth beneath the water line) at the end of the melt season decreased by about $1.3 \mathrm{~m}$ in most of the deep water portion of the Arctic Ocean, from $3.1 \mathrm{~m}$ in 19581976 to $1.8 \mathrm{~m}$ in the $1990 \mathrm{~s}$. Winsor (2001), however, found no trend towards a thinning ice cover during the 1990s. Since these observations are restricted in time and space, their implications are uncertain; it is conceivable that the projections using coupled general circulation models are

Corresponding author: Yukimasa Adachi, Meteorological Research Institute, 1-1 Nagamine, Tsukuba 305-0052, Japan. E-mail: yadachi@mri-jma.go.jp. @2006, the Meteorological Society of Japan. also inexact (Fig. 9.9 of IPCC 2001). Because of these uncertainties, the treatment of sea ice thickness as a boundary condition for typical AGCMs has been simple (e.g., for most AGCMs in AMIP or AMIP2, constant and uniform in time and space, or given by the local concentration fraction multiplied by a constant value).

Few studies have investigated the impact of changing sea ice thickness on the atmosphere. The relationship between sea ice thickness and sea ice surface temperature (i.e., sea ice surface temperature is higher when sea ice is thinner) has already been expressed (Thorndike 1992), but only in a toy model assuming simple heat balance at the sea ice surface that is probably different from reality. Because sea ice thickness affects the atmosphere through heat fluxes at the sea ice surface, it is important to comprehend in detail the realistic heat balance at the sea ice surface. In this study, we use an AGCM to investigate how various sea ice thicknesses affect the temperature and heat balance at the surface in the Northern Hemisphere sea ice region. In addition, we discuss the response of the extra-tropical atmospheric circulation to sea ice thickness variability, and examine its importance relative to atmospheric variability.

\section{Methodology}

\subsection{Treatment of sea ice in the model}

The model used for this study is a version of the AGCM developed jointly by the Meteorological Research Institute (MRI) and the Japan Meteorological Agency (JMA). The model resolution is about $180 \mathrm{~km}$ horizontally with 40 vertical layers (TL95L40). Details can be found in Mizuta et al. (2005).

The sea ice formulation used in the AGCM is a single layer. For the standard simulation, the sea ice thickness $\left(H_{i}\right)$ is set constant and uniform in time and space over the entire sea ice extent. The sea ice coverage is given as a boundary condition without permitting partial coverage, meaning there is no lead. Snow on sea ice is not considered. The albedo of the sea ice is set constant $(=0.8)$. The temperature at the bottom of sea ice $\left(T_{b}\right)$ is fixed as the freezing point of seawater $\left(=-1.64^{\circ} \mathrm{C}\right)$. The temperature on the sea ice surface $\left(T_{s}\right)$ is a prognostic variable, calculated by

$$
C_{i} \frac{d T_{s}}{d t}=H C-R_{L W}+R_{S W}-F_{S H}-F_{L H} .
$$

Here, $C_{i}$ is heat capacity of the sea ice surface; $F_{S H}$ and $F_{L H}$ are upward sensible and latent heat fluxes calculated with bulk equations similar to Louis et al. (1982); $R_{L W}$ is the upward net longwave radiation; $R_{S W}$ is downward net shortwave radiation; and $H C$ is heat conduction through the sea ice from the bottom to the surface, expressed as

$$
H C=\lambda \frac{T_{b}-T_{s}}{H_{i}},
$$

where $\lambda$ is the heat conduction coefficient $(=2.03$ $\mathrm{W} \mathrm{K} \mathrm{K}^{-1} \mathrm{~m}^{-1}$.

\subsection{Experiment design}

In order to examine the effect of sea ice thickness change, we conducted 20 simulations in which only sea ice thickness was altered $(0.01 \mathrm{~m}, 0.05 \mathrm{~m}, 0.1 \mathrm{~m}, 0.15 \mathrm{~m}, 0.2-1 \mathrm{~m}$ (at intervals of $10 \mathrm{~cm}$ ), $1.5 \mathrm{~m}, 2 \mathrm{~m}, 3 \mathrm{~m}, 4 \mathrm{~m}, 5 \mathrm{~m}, 6 \mathrm{~m}$, and $10 \mathrm{~m})$, retaining other common boundary conditions. The 


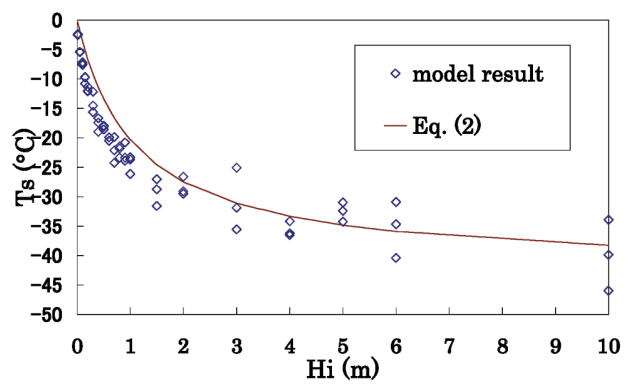

Fig. 1. Scatter plot of sea ice thickness $\left(H_{i}\right)$ versus sea ice surface temperature $\left(T_{s}\right)$ averaged over the region north of 80 ${ }^{\circ} \mathrm{N}$. Each dot indicates the January mean of individual simulations. There are $60(=20 \times 3)$ dots in this figure, since 3 years of data of each of the 20 simulations are used. The curve represents Eq. (2).

sea ice coverage and sea surface temperature were given for the observed monthly mean climatological (1982-1993 average) boundary conditions (Reynolds and Smith 1994). Each of the 20 simulations was integrated for 47 months using the same initial state, and the last 3 years (36 months) of data of each simulation were used for the analysis.

\section{Results}

We first examine the impact of sea ice thickness on sea ice surface temperature that is directly affected by sea ice thickness through the relation by Eq. (1). Figure 1 plots the sea ice surface temperature averaged over the region north of $80^{\circ} \mathrm{N}$ in January with respect to the sea ice thickness. Each dot indicates the January mean of individual simulations. We use 3 years' data for each of the 20 simulations, so there are $60(=20 \times 3)$ dots in this figure.

The results indicate a close (though not linear) relationship between sea ice surface temperature and sea ice thickness. The sea ice surface temperature is low when the sea ice is thick, and thinner sea ice leads to a higher temperature. The sea ice surface temperature difference to thickness change is greater when the sea ice is thinner (i.e., the effect of sea ice thickness on the temperature increases when the sea ice is thinner). This relationship is consistent with Thorndike's (1992) equation of sea ice surface temperature (represented by the curve in Fig. 1):

$$
T_{s}=\frac{-\left(\frac{A}{n}-\frac{D}{2}\right) n H_{i}}{k n+B H_{i}} .
$$

Here, $D$ is atmospheric heat transport $\left(=100 \mathrm{~W} \mathrm{~m}^{-2}\right) ; A=$ $\sigma T_{f}^{4}\left(=320 \mathrm{~W} \mathrm{~m} \mathrm{~m}^{-2}\right)$ with $T_{f}=273 \mathrm{~K} ; \sigma$ is the StefanBoltzmann constant $\left(=5.7 \times 10^{-8} \mathrm{~W} \mathrm{~m}^{-2} \mathrm{~K}^{-4}\right) ; n$ is optical depth for winter $(=2.5) ; B=4 \sigma T_{f} 3\left(=4.6 \mathrm{~W} \mathrm{~m}^{-2} \mathrm{~K}^{-1}\right)$; and $k$

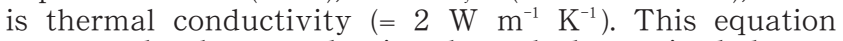
assumes that heat conduction through the sea ice balances with net longwave radiation at the sea ice surface. Net longwave radiation $(L)$ and heat conduction $(H)$ are defined as

$$
L=\frac{B}{n} T_{s}+\frac{A}{n}-\frac{D}{2},
$$

and

$$
H=-\frac{k T_{s}}{H_{i}} .
$$

Equation (3) states that net longwave radiation increases linearly with the sea ice surface temperature. However, the sea ice surface temperature in Eq. (2) is $4-5^{\circ} \mathrm{C}$ higher than that of our numerical experiment when sea ice is thin.

Next, we analyze the heat balance at the sea ice surface in winter. Figure 2 plots the heat fluxes (sensible heat $\left(F_{S H}\right)$,

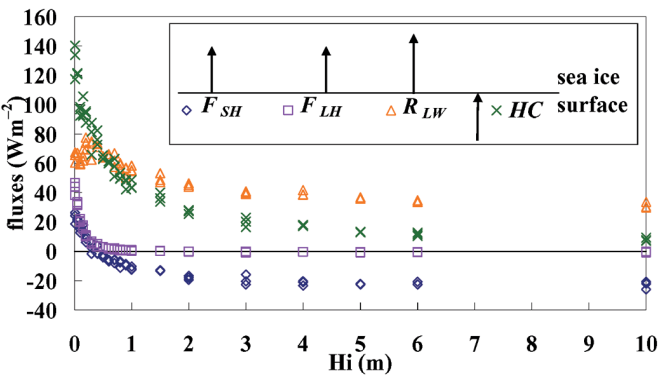

Fig. 2. Same as Fig. 1 except for sea ice thickness $\left(H_{i}\right)$ versus the heat fluxes at the sea ice surface (sensible heat $\left(F_{S H}\right)$, latent heat $\left(F_{L H}\right)$, net longwave radiation $\left(R_{L W}\right)$, and heat conduction through the sea ice $(H C))$. Positive values indicate upward fluxes. Directions of fluxes are also indicated in the legend.

latent heat $\left(F_{L H}\right)$, net longwave radiation $\left(R_{L W}\right)$, and heat conduction $(H C)$ ) at the sea ice surface for each of the 20 simulations with regard to sea ice thickness in the same region and month as for Fig. 1. Shortwave radiation is not included because of no solar radiation in January in the Arctic region. Positive values indicate upward fluxes (i.e., from sea ice surface to air for $F_{S H}, F_{L H}$ and $R_{L W}$, and from sea ice bottom to surface for $H C$ ).

These fluxes are generally greater in magnitude and more sensitive to the sea ice thickness change when the sea ice is thinner, while they vary minimally when sea ice is thicker than $4 \mathrm{~m} . F_{L H}$ is negligible when sea ice is thicker than $50 \mathrm{~cm}$ (corresponding to the sea ice surface temperature of $-18^{\circ} \mathrm{C}$ in Fig. 1). $R_{L W}$ generally increases with the temperature, but changes little $\left(60-70 \mathrm{~W} \mathrm{~m}^{-2}\right)$ and appears independent of sea ice thickness when the sea ice is thinner than $50 \mathrm{~cm} . F_{S H}$ is negative (downward) when the sea ice is thicker than $50 \mathrm{~cm}$, and positive (upward) when the sea ice is thinner than $50 \mathrm{~cm}$.

According to our experiment results, not only $R_{L W}$ and $H C$ but also $F_{S H}$ and $F_{L H}$ play important roles in the heat balance at the sea ice surface. $R_{L W}$ is balanced with $H C$ only when sea ice thickness is between $50 \mathrm{~cm}$ and $1 \mathrm{~m}$. When the sea ice is thinner than $50 \mathrm{~cm}$, the contribution of $F_{S H}$ and $F_{L H}$ can not be neglected, so the four kinds of fluxes balance each other out. When sea ice is thicker than $1 \mathrm{~m}, R_{L W}$ balances with $H C$ and $F_{S H}$. Moreover, when sea ice is sufficiently thick, cooling with $R_{L W}$ is mainly compensated by heating with downward $F_{S H}$, since $H C$ is small. In this way, the elements contributing the heat balance at the sea ice surface differ, depending on sea ice thickness.

Here, we focus on the rates of change in these fluxes with respect to sea ice surface temperature. Figure 3a plots the heat fluxes $\left(F_{S H}, F_{L H}, R_{L W}\right.$, and $\left.H C\right)$ with respect to sea ice surface temperature. When the sea ice surface temperature is colder than $-35^{\circ} \mathrm{C}$ (corresponding to sea ice thickness of $4 \mathrm{~m}$ ), the rates of change in $F_{S H}$ and $F_{L H}$ are small because of strong stability over the surface, so those of $R_{L W}$ and $H C$ are equivalent. In the temperature range between -35 and -18 ${ }^{\circ} \mathrm{C}, F_{L H}$ is still negligible, so the rates of change in $R_{L W}, H C$, and $F_{S H}$ are balanced. When sea ice surface temperature is warmer than $-18^{\circ} \mathrm{C}$, the changes of $H C$ and that of $F_{S H}$ and $F_{L H}$ balance each other out since $R_{L W}$ remains nearly constant. As a result, $H C$ changes linearly in this temperature range, implying that the total heat flux from the sea ice surface to the atmosphere linearly increases to the sea ice surface temperature. Since the heat capacity of sea ice surface $\left(C_{i}\right)$ is negligible, $H C$ is almost equal to the net surface heat flux from the ocean to the atmosphere except during melting season.

The linear increase of $R_{L W}$ with the temperature increase leveled off at temperatures higher than $-18^{\circ} \mathrm{C}$. This result is attributed to the increase in downward longwave radiation from the atmosphere to the sea ice surface, which corresponds to the increase of clouds (Fig. 3b). It also 
(a)

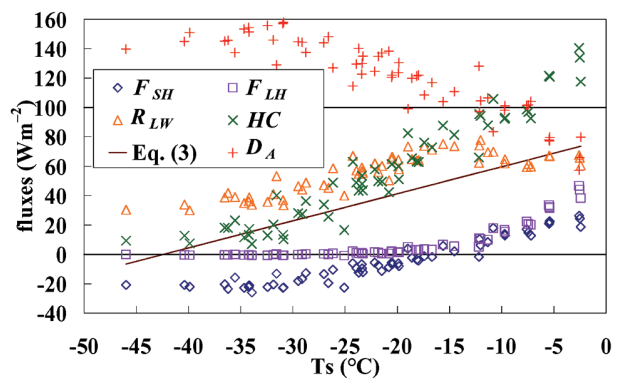

(b)

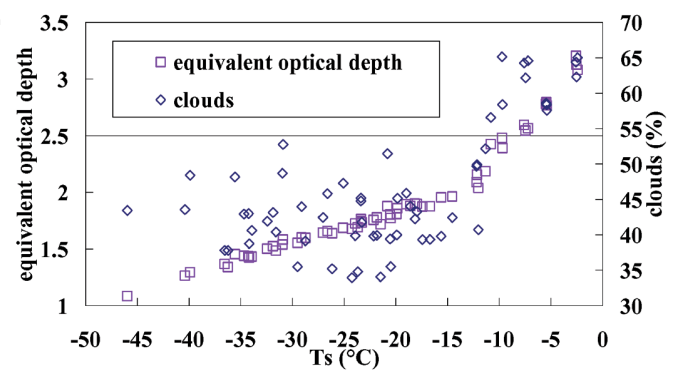

Fig. 3. Same as Fig. 2 except for sea ice surface temperature $\left(T_{s}\right)$ versus (a) heat fluxes and atmospheric heat transport $\left(D_{A}\right)$, and (b) equivalent optical depth $\left(n_{e}\right)$ and clouds. Each dot indicates the results of the AGCM simulations. The line represents Eq. (3).

corresponds to the drastic increase of $F_{L H}$, which is probably due to the decline in stability over sea ice, consistent with the reverse of the temperature gradient between the surface and the air near the sea ice surface temperature of $-18^{\circ} \mathrm{C}$. This reverse is also found for the direction of $F_{S H}$. The critical sea ice surface temperature of $-18^{\circ} \mathrm{C}$ in our AGCM is related to the structural change of the surface boundary layer (i.e., the surface inversion layer dissolves).

Though $D$ and $n$ are set constant in Eq. (3), in reality they should vary with atmospheric circulation change in response to ice thickness (i.e. sea ice surface temperature). The atmospheric heat transport in the $\operatorname{AGCM}\left(D_{A}\right)$ is depicted in Fig. 3a. $D_{A}$ varies $60-160 \mathrm{~W} \mathrm{~m}^{-2}$ in the thickness (or temperature) range. It is when sea ice is about $15 \mathrm{~cm}$ $\left(T_{s}=-10^{\circ} \mathrm{C}\right)$ that $D_{A}$ is comparable to $D\left(100 \mathrm{~W} \mathrm{~m}^{-2}\right)$ in Eq. (2). $D_{A}$ is $150 \mathrm{~W} \mathrm{~m}^{-2}$ when the sea ice is thicker than $2 \mathrm{~m}$ ( $T_{s}$ warmer than $-30^{\circ} \mathrm{C}$ ), and gradually becomes smaller for thinner sea ice in the warmer Arctic region, indicating that sea ice thickness affects atmospheric circulation. The equivalent optical depth in the AGCM experiments $\left(n_{e}\right)$ is evaluated by substituting $T_{s}, D_{A}$, and $R_{L W}$ into Eq. (3), as illustrated in Fig. 3b. In the temperature range, $n_{e}$ varies from 1 to 3 . It is also when sea ice is $15 \mathrm{~cm}$ that $n_{e}$ is 2.5 (equivalent to $n$ in Eq. (2)). $n_{e}$ is larger for thinner ice (warmer $T_{s}$ ), and its change rate to sea ice surface temperature is greater for $T_{s}$ warmer than $-18^{\circ} \mathrm{C}$, consistent with the changes in clouds (Fig. $3 \mathrm{~b}$ ), $F_{L H}$, and $R_{L W}$ (Fig. 3a).

We investigate the potential impact of sea ice thickness other than the vicinity of the surface in the winter polar region. The variation of sea ice thickness influences the atmosphere through the heat fluxes from sea ice surface to air. Though the relationship between sea ice thickness and heat fluxes at the sea ice surface is not linear, total heat flux from the surface to the air (equivalent to heat conduction) changes linearly in proportion to sea ice surface temperature (Fig. 3a). Thus, we made regressions of the zonal mean air temperature and zonal wind to the sea ice surface temperature, instead of the thickness, in January averaged over the region north of $80^{\circ} \mathrm{N}$ (Fig. 4).

Figure 4a indicates high positive correlation in the region from the North Pole to $50-60^{\circ} \mathrm{N}$ around the sea ice edge. Sea ice thickness appears to influence the air temperature over the surrounding land and sea out of the sea ice
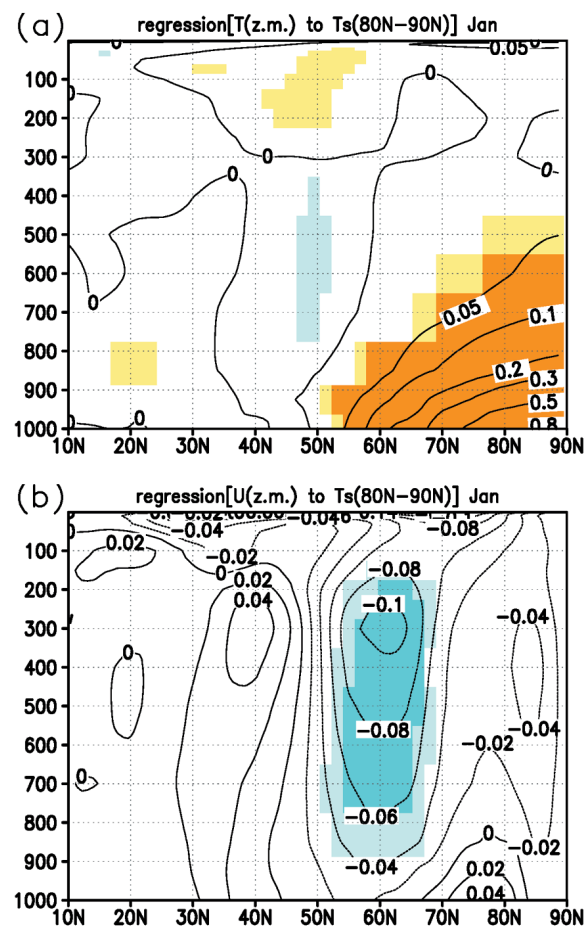

Fig. 4. The meridional-vertical cross section for the zonal mean (a) air temperature $\left({ }^{\circ} \mathrm{C}\right)$ and (b) zonal wind $\left(\mathrm{m} \mathrm{s}^{-1}\right)$ regressed to the sea ice surface temperature averaged over the same region as in Fig. 1 in January. Light (dark) shading indicates statistical significance at the 95 (99) \% level.

region, probably due to being directly mixed by atmospheric disturbances. The influence extends from the surface to an altitude of $500 \mathrm{hPa}$, a large portion of the troposphere in the Arctic region. The magnitude of the influence is more than $0.05^{\circ} \mathrm{C}$ per sea ice surface temperature variation of $1^{\circ} \mathrm{C}$. The thinner sea ice leads to a higher temperature in the upper air over the Arctic, which moderates the temperature gradient between the polar region and the mid-latitudes, consistent with the weakened westerly wind in the upper air around $60^{\circ} \mathrm{N}$ (Fig. $4 \mathrm{~b}$ ). The magnitude of the influence is $0.1 \mathrm{~m} \mathrm{~s}^{-1}$ at the maximum per sea ice surface temperature variation of $1^{\circ} \mathrm{C}$.

\section{Summary and discussions}

In our study using an AGCM, close relationships are found between sea ice thickness, sea ice surface temperature, and heat fluxes at the sea ice surface in the winter Arctic region. As the sea ice thins, the sea ice surface temperature increases, accompanied by heat balance change. Not only longwave radiation and heat conduction (as in the toy model) but also sensible and latent heat fluxes play important roles in the heat balance at the sea ice surface. When the sea ice is thick (more than $1 \mathrm{~m}$ ), longwave cooling is balanced with heating by heat conduction and downward sensible heat flux. When the sea ice is sufficiently thin (less than $50 \mathrm{~cm}$ ), cooling with sensible and latent heat fluxes make a substantial contribution to heat balance at the sea ice surface, canceling out the increase of downward longwave heating associated with cloud change. In the heat balance change, only heat conduction increases linearly with respect to the sea ice surface temperature at any sea ice thickness range.

The effect of the difference of sea ice thickness as discussed above occurs only in the winter. Sea ice melts at the surface in summer, and the sea ice surface temperature nears the freezing point. Because the temperature at the 


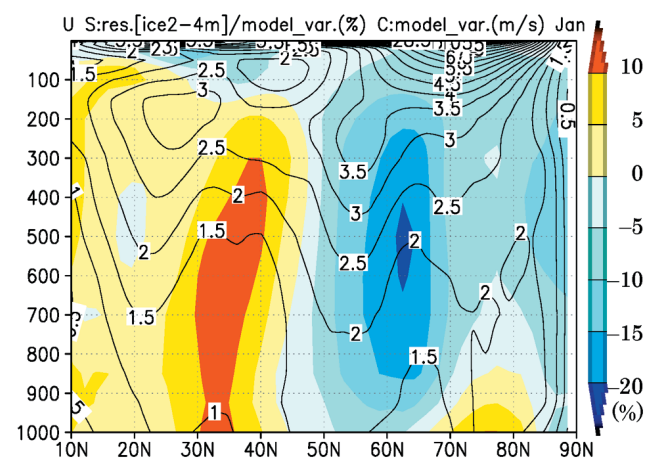

Fig. 5. The meridional-vertical cross section of zonal mean zonal wind response (shading) for possible sea ice thickness variability $(2-4 \mathrm{~m})$ as the ratio relative to year-to-year atmospheric model internal variability in percent, and year-to-year atmospheric internal variability in the model (contours) with the contour interval $0.5 \mathrm{~m} \mathrm{~s}^{-1}$.

bottom of the sea ice is fixed at the freezing point $(=-1.64$ ${ }^{\circ} \mathrm{C}$ ) in our AGCM, the temperature gradient between the surface and the bottom of the sea ice is small. Therefore, the heat conduction is almost zero, independent of the sea ice thickness. However, influences of the sea ice thickness on the melting rate are not included in this experiment, because the ice-albedo feedback (though is not active in winter) does not work in experiments using AGCMs.

The essential differences between the AGCM and the toy model (Thorndike 1992) are the inclusion of the sensible and latent heat fluxes, and the assumptions of constant heat transport $(D=100)$ and optical depth $(n=2.5)$. The behavior of $R_{L W}$ with respect to surface temperature change is apparently different from Eq. (3), which is based on the assumptions of constant $D$ and $n$ (the line in Fig. 3a). However, our experiments are consistent with Eq. (2) as presented in Fig. 1, because $H C$ changes linearly with respect to the sea ice surface temperature, the same as is expressed by rhs. of Eq. (3).

When sea ice is thick (sea ice surface temperature is low), $D$ and $n$ in Eq. (3) do not agree with those in the AGCM, and $R_{L W}$ also differs from $L$ in Eq. (3). However, the relationships between ice thickness and ice surface temperature (Fig. 1) coincide because of the equivalency of heat conduction between the models (Fig. 3a); the downward sensible heat flux compensates for the discrepancy of longwave radiation.

When sea ice is thin (sea ice surface temperature is high), $D$ and $n$ in Eq. (3) are similar to $D_{A}$ and $n_{e}$ in the AGCM; $R_{L W}$ is also close to $L$ in Eq. (3). However, a greater $H C$ than that estimated by Eq. (4) is needed to compensate for cooling with sensible and latent heat fluxes that the toy model does not take into account. Consequently, the simulated $T_{s}$ is lower than that estimated by Eq. (2) for the same sea ice thickness.

Local responses to ice anomalies indicate similar behavior between ice area and thickness changes, e.g., upward surface heat fluxes increase and near-surface temperature rises where sea ice reduces (e.g., Parkinson et al. 2001). Remote responses depend on locations of ice anomalies. Magnusdottir et al. (2004) and Alexander et al. (2004) confirmed that the response to reduced ice extent to the east of Greenland resembles the negative phase of the Arctic Oscillation (AO)/North Atlantic Oscillation. Although thickness anomalies are set to the entire sea ice extent in our experiments, the zonal mean zonal wind responses to reduced ice thickness are reminiscent of the negative phase of the AO.

The importance of atmospheric circulation responses should be estimated compared with atmospheric internal variability. A 10-year control simulation with constant $(2 \mathrm{~m})$ sea ice thickness is performed to estimate the atmospheric internal variability in the model. The simulated interannual variability (contours in Fig. 5) agrees well with the observed one (not shown). The ratio of the response to possible sea ice thickness variability relative to year-to-year atmospheric model internal variability is illustrated in Fig. 5. The response is calculated as a regression coefficient $\left(\mathrm{m} \mathrm{s}^{-1} /{ }^{\circ} \mathrm{C}\right)$ (Fig. $\left.4 \mathrm{~b}\right)$ multiplied by $5\left({ }^{\circ} \mathrm{C}\right)$. The possible sea ice thickness variability is assumed to be 2 to $4 \mathrm{~m}$, based on observed typical variation (McLaren et al. 1992; Laxon et al. 2003). It corresponds to $5^{\circ} \mathrm{C}$ of sea ice surface temperature variation (Fig. 1), and is equivalent to $16 \mathrm{~W} \mathrm{~m}^{-2}$ of total heat flux variation (Fig. 3a). The magnitude of the response of the upper zonal wind to the possible sea ice thickness variability is $10-20 \%$ of the atmospheric interannual variability. This signal is large enough to investigate more detailed atmospheric circulation response to sea ice thickness variability.

The experiment design is somewhat idealized (e.g., no snow on the ice, no leads in the ice (ice fraction $=100 \%$ ) and no spatial variability in the ice thickness). Therefore, caution is advised in applying these results to nature.

\section{Acknowledgements}

The authors would like to thank the members of MRI and JMA for their contribution to the development of the model, and Dr. A. Kitoh and Mr. M. Hosaka for their helpful advice and encouragement. We also thank the editor and two anonymous reviewers for their comments and suggestions.

\section{References}

Alexander, M. A., U. S. Bhatt, J. E. Walsh, M. S. Timlin, J. S. Miller, and J. D. Scott, 2004: The atmospheric response to realistic Arctic sea ice anomalies in an AGCM during winter. $J$. Climate, 17, 890-905.

Bourke, R. H., and A. S. McLaren, 1992: Contour mapping of Arctic Basin ice draft and roughness parameters. J. Geophys. Res., 97, 17715-17728.

Flato, G. M., and D. Ramsden, 1997: Sensitivity of an atmospheric general circulation model to the parameterization of leads in sea ice. Ann. Glaciol., 25, 96-101.

IPCC, 2001: Climate Change 2001: The Scientific Basis. J. T. Houghton et al. Eds., Cambridge University Press, UK, 881 pp.

Laxon, S., N. Peacock, and D. Smith, 2003: High interannual variability of sea ice thickness in the Arctic region. Nature, 425, 947-950.

Louis, J. F., M. Tiedtke, and J. F. Geleyn, 1982: A short history of the operational PBL-parameterization at ECMWF. Workshop on Planetary boundary layer parameterization, ECMWF, Reading, U.K., 25-27 November 1981, 59-80.

Magnusdottir, G., C. Deser, and R. Saravanan, 2004: The effects of North Atlantic SST and sea ice anomalies on the winter circulation in CCM3. Part I: Main features and storm track characteristics of the response. J. Climate, 17, 857-876.

McLaren, A. S., J. E. Walsh, R. H. Bourke, R. L. Weaver, and W. Wittman, 1992: Variability in sea-ice thickness over the North Pole from 1977 to 1990. Nature, 358, 224-226.

Mizuta, R., K. Oouchi, H. Yoshimura, A. Noda, K. Katayama, S. Yukimoto, M. Hosaka, S. Kusunoki, H. Kawai, and M. Nakagawa, 2006: 20km-mesh global climate simulations using JMA-GSM model. J. Meteor. Soc. Japan, 84, 165-185.

Parkinson, C. L., D. Rind, R. J. Healy, and D. G. Martinson, 2001: The impact of sea ice concentration accuracies on climate model simulations with the GISS GCM. J. Climate, 14, 2606-2623.

Reynolds, R. W., and T. M. Smith, 1994: Improved global sea surface temperature analysis using optimum interpolation. J. Climate, 7, 929-948.

Rothrock, D. A., Y. Yu, and G. A. Maykut, 1999: Thinning of the Arctic sea-ice cover. Geophys. Res. Lett., 26, 3469-3472.

Thorndike, A. S., 1992: A toy model linking atmospheric thermal radiation and sea ice growth. J. Geophys. Res., 97, 9401-9410.

Winsor, P., 2001: Arctic sea ice thickness remained constant during the 1990s. Geophys. Res. Lett., 28, 1039-1041.

Manuscript received 6 February 2006, accepted 24 April 2006

SOLA: http://www.jstage.jst.go.jp/browse/sola/ 